\title{
Avaliação dos currículos de formação de professores para o ensino fundamental
}

\author{
BERNARDETE A. GATTI* \\ MARINA M. R. NUNES** \\ NELSON A. S. GIMENES*** \\ SANDRA G. UNBEHAUM**** \\ GISELA L. B. P. TARTUCE*****
}

\section{RESUMO}

O presente estudo analisa o que se propóe como disciplinas formadoras nas instituições de ensino superior dos cursos de Pedagogia. A análise focalizou os currículos e ementas de cursos presenciais de licenciatura em Pedagogia, que respondem pela formação de professores do $1^{\circ}$ ao $5^{\circ}$ ano do ensino fundamental e da educaçáo infantil. O texto apresenta as características desses cursos no Brasil e, entre elas, destacam-se alguns aspectos, tais como: a fragmentaçáo observada nas grades curriculares, que apresentam um conjunto disciplinar bastante disperso, e a ênfase das ementas, que registram preocupação com as justificativas sobre "o porquê" ensinar - o que, de certa forma, contribuiria para evitar que essas matérias se transformassem em meros receituários; entretanto, só de forma muito incipiente registram "o quê" e "como" ensinar.

Palavras-chave: ensino superior, currículo, formação de professores, avaliação da educação.

* Superintendente Educacional da Fundação Carlos Chagas (gatti@fcc.org.br).

** Pesquisadora da Fundação Carlos Chagas e orientadora Educacional do Colégio Santa Cruz (mnunes@fcc.org.br).

*** Pesquisador da Fundação Carlos Chagas (ngimenes@fcc.org.br).

**** Pesquisadora da Fundação Carlos Chagas (sandrau@fcc.org.br).

***** Pesquisadora da Fundação Carlos Chagas (gtartuce@fcc.org.br). 


\section{RESUMEN}

El presente estudio analiza lo que se ofrece como asignaturas formativas en las instituciones de enseñanza superior de los cursos de Pedagogía. El análisis focalizó los currículos y los planes de cursos presenciales de licenciatura en Pedagogía, que se encargan de la formación de profesores de $1^{\circ}$ a $5^{\circ}$ año de la enseñanza fundamental y de la educación infantil. El texto presenta las características de estos cursos en Brasil y, de ellas, destaca algunos aspectos tales como: la fragmentación observada en los currículos, que presentan un conjunto de asignaturas bastante disperso, y el énfasis de los planes de curso, que registran preocupaciones sobre las justificativas sobre "el porqué" de enseñar - lo que, de cierta manera, contribuiría a evitar que estas materias se transformasen en meros recetarios; sin embargo, sólo de forma muy incipiente registran "qué" y "cómo" enseñar.

Palabras clave: enseñanza superior, currículo, formación de profesores, evaluación de la educación.

\section{ABSTRACT}

This study analyzes what is proposed as teacher training disciplines in higher education Pedagogy courses. The analysis focused on the curricula and descriptions of in-class teacher training courses in Pedagogy, which are responsible for training teachers from the 1st through the 5th grade of elementary school and kindergarten. The paper presents the features of these courses in Brazil and, among them, highlights some aspects such as fragmentation in the curricula showing a quite dispersed set of disciplines, and the emphasis of the descriptions showing a concern with justifying "why" to teach - which, in a way, would contribute to avoiding that these disciplines become mere recipes. However, it is only in a very incipient manner that they register "what" and "how" to teach.

Keywords: higher education, curriculum, teacher education, course evaluation. 
Cada vez mais a questão da formação de professores assume importância ante as exigências que são colocadas à educação básica de crianças e adolescentes na sociedade. Considerando que os cursos formadores de professores passaram a ser oferecidos predominantemente em nível superior, que obedecem a recentes orientaçôes das Diretrizes Curriculares Nacionais, procurou-se examinar, neste estudo, as características que vem assumindo a atual formação de docentes para as primeiras séries do ensino fundamental e a educação infantil.

A pesquisa apresentada analisou os currículos e as ementas de cursos presenciais de licenciatura em Pedagogia, por responderem majoritariamente pela formação de professores do $1^{\circ}$ ao $5^{\circ}$ ano do ensino fundamental e da educação infantil. Procedeu-se a um mapeamento de propostas curriculares desses cursos, considerando os diversos tipos de instituiçóes de ensino superior que os oferecem. Como as Diretrizes Curriculares Nacionais para esses cursos são amplas, e a estruturação do currículo fica a cargo de cada instituição, procurou-se obter um panorama do que está sendo proposto como formação nas instituiçôes de ensino superior, identificando ênfases que lhes estão sendo atribuídas e adequação às demandas profissionais: o exercício da docência nos primeiros anos da educação básica.

\section{OS CURSOS DE PEDAGOGIA NO BRASIL}

Este tópico destina-se a oferecer dados sobre as características gerais dos cursos de licenciatura em Pedagogia, pois são os cursos que têm como eixo principal a formação de professores para os primeiros anos do ensino fundamental e a educação infantil. Foram utilizadas as informaçóes disponibilizadas pelo Instituto Nacional de Estudos e Pesquisas Educacionais Anísio Teixeira (Inep), por meio das sinopses estatísticas da educação superior de 2001, 2004 e 2006 (último ano disponível no início desta pesquisa). As informaçóes foram analisadas segundo a categoria administrativa ${ }^{1}$ das instituiçôes de educação superior (IES), bem como a sua organização acadêmica ${ }^{2}$. Essa descrição contribuirá para a compreensão das características básicas desses cursos, e posteriormente, para justificar a amostra de cursos selecionados para o estudo mais detalhado de seus currículos.

\footnotetext{
${ }^{1}$ A instituição é classificada como pública (federal, estadual ou municipal) ou privada (particular ou filantrópica, comunitária ou confessional).

${ }^{2} \mathrm{O}$ curso está vinculado a universidades ou centros universitários, faculdades integradas, isoladas, escolas ou institutos superiores de educação (ISE).
} 


\subsection{Panorama institucional}

De acordo com os dados do Inep ${ }^{3}$, existiam no Brasil, em 2006, 1.562 cursos de graduação presencial em Pedagogia, com cerca de 281.000 alunos matriculados. No que diz respeito ao número de cursos, a maioria deles (56\%) era oferecida por IES privadas (32\% delas particulares e $24 \%$ comunitárias, confessionais ou filantrópicas); $32 \%$ ofertados por instituiçóes estaduais; apenas $10 \%$ por instituiçóes federais e $2 \%$ por instituiçóes municipais (Tabela 1). A predominância das instituiçôes privadas na formação de pedagogos fica ainda mais evidente ao se verificar que $62 \%$ dos alunos matriculados estáo nessas instituições.

Tabela 1 - Cursos de Pedagogia e respectivas matrículas, segundo a categoria administrativa das IES

\begin{tabular}{l|l|r|r|r|r}
\hline \multirow{2}{*}{ Categoria Administrativa } & \multicolumn{2}{|c|}{ Cursos } & \multicolumn{2}{c}{ Alunos matriculados } \\
\cline { 3 - 6 } & Federal & N & $\%$ & N & $\%$ \\
\hline \multirow{3}{*}{ Pública } & Estadual & 164 & 10 & 36.892 & 13 \\
& Municipal & 495 & 32 & 63.867 & 23 \\
& Privada & 36 & 2 & 5.327 & 2 \\
\hline \multirow{2}{*}{ Total } & Particular & 491 & 32 & 104.566 & 37 \\
& Filant. & 376 & 24 & 70.520 & 25 \\
\hline
\end{tabular}

Fonte: MEC/Inep/Daes, 2006.

Quanto ao tipo de instituição, a maioria dos cursos (71\%) era oferecida por instituiçóes universitárias (universidades ou centros universitários), que têm autonomia para criar cursos. Mais de um quarto deles e dos discentes matriculados estavam vinculados a faculdades integradas, isoladas e institutos superiores de educação (Tabela 2).

\footnotetext{
${ }^{3} \mathrm{Na}$ Sinopse Estatística da Educação Superior - 2006, não havia dados sobre os cursos de graduação, segundo a unidade federativa (Brasil, 2006a).
} 
Tabela 2 - Cursos de Pedagogia e respectivas matrículas, segundo a organização acadêmica das IES

\begin{tabular}{l|c|r|r|c}
\hline \multirow{2}{*}{ Organização Acadêmica } & \multicolumn{2}{|c|}{ Cursos } & \multicolumn{2}{c}{ Alunos matriculados } \\
\cline { 2 - 5 } & N & \multicolumn{1}{c|}{$\%$} & $\mathbf{N}$ & $\%$ \\
\hline Universidades & 989 & 63 & 168.728 & 60 \\
Centros Universitários & 125 & 8 & 31.377 & 11 \\
Faculdades Integradas & 70 & 5 & 14.423 & 5 \\
Faculdades Isoladas, & 378 & 24 & 66.644 & 24 \\
Escolas e ISE & $\mathbf{1 . 5 6 2}$ & $\mathbf{1 0 0}$ & $\mathbf{2 8 1 . 1 7 2}$ & $\mathbf{1 0 0}$ \\
\hline Total & & &
\end{tabular}

Fonte: MEC/Inep/Daes, 2006.

Com relação à distribuição regional, segundo a organização acadêmica, temos respectivamente $31 \%$ e $69 \%$ de universidades e centros universitários na Regiáo Sudeste, onde também se situam $62 \%$ das faculdades integradas e $52 \%$ das isoladas. A Região Sul concentra $27 \%$ das universidades, $14 \%$ dos centros universitários e $15 \%$ de faculdades isoladas.

\subsection{Número de cursos e de alunos matriculados em Pedagogia em 2001, 2004 e 2006}

A respeito do número de cursos de Pedagogia entre 2001 e 2006, a comparação dos dados aponta que houve um crescimento de cerca de $70 \%$ na oferta desse tipo de curso, sobretudo aqueles vinculados às instituiçóes estaduais (170\%) e às privadas (98\%). No entanto, é possível observar também que tal crescimento se deu predominantemente entre 2001 e 2004, uma vez que o percentual de aumento no número desses cursos entre 2004 e 2006 foi de apenas $9 \%$.

Quanto ao número de alunos matriculados, em 2001 havia 220.906 estudantes cursando Pedagogia e, em 2006, cerca de 281.000, verificando-se um acréscimo de $27 \%$, ou seja, o número de alunos não aumentou na mesma medida que o número de cursos. A ampliação do número de cursos de Pedagogia não foi acompanhada por um crescimento da demanda. Uma explicação possível é a de que o aumento de cursos e matrículas verificado no início da década foi em razáo da prescrição, pela Lei de Diretrizes e Bases (LDB 9.394/96), de que a formação docente para a educação básica deverá ser feita em nível superior. Uma vez atendida a demanda de 
credenciamento em nível superior dos professores em exercício que antes tinham apenas o nível médio, é provável que a procura por esses cursos se estabilize em um patamar mais baixo. Devemos considerar, especialmente nas Regióes Sudeste e Sul, a redução do crescimento demográfico das geraçôes mais jovens e, ainda, o fator atratividade da carreira que se torna pequeno nas regióes mais desenvolvidas.

Com relação à categoria administrativa das instituiçóes que oferecem o curso de Pedagogia, é importante destacar que o maior crescimento das matrículas nos três anos analisados deu-se nas IES estaduais, correspondendo a 95\% de aumento entre 2001 e 2006. Por outro lado, embora as instituiçóes privadas tenham ampliado o número de alunos matriculados em mais de 30\%, nas instituiçóes confessionais, filantrópicas ou comunitárias houve, ao contrário, redução de $6 \%$ do número de matriculados (Tabela 3).

Tabela 3 - Cursos de Pedagogia e respectivas matrículas, segundo a categoria administrativa das IES

\begin{tabular}{|c|c|c|c|c|}
\hline \multicolumn{3}{|c|}{ Categoria Administrativa } & \multirow{2}{*}{$\frac{\text { No de cursos }}{129}$} & \multirow{2}{*}{$\frac{\text { No de alunos }}{32.528}$} \\
\hline \multirow{6}{*}{2001} & \multirow{3}{*}{ Pública } & Federal & & \\
\hline & & Estadual & 185 & 32.792 \\
\hline & & Municipal & 26 & 5.120 \\
\hline & \multirow{2}{*}{ Privada } & Particular & 307 & 75.797 \\
\hline & & Comum./Confes./Filant. & 272 & 74.669 \\
\hline & \multicolumn{2}{|l|}{ Total } & 919 & 220.906 \\
\hline \multirow{6}{*}{2004} & \multirow{3}{*}{ Pública } & Federal & 153 & 40.714 \\
\hline & & Estadual & 466 & 50.277 \\
\hline & & Municipal & 38 & 6.897 \\
\hline & \multirow{2}{*}{ Privada } & Particular & 467 & 99.216 \\
\hline & & Comum./Confes./Filant. & 313 & 80.922 \\
\hline & \multicolumn{2}{|l|}{ Total } & 1.437 & 278.026 \\
\hline \multirow{6}{*}{2006} & \multirow{3}{*}{ Pública } & Federal & 164 & 36.892 \\
\hline & & Estadual & 495 & 63.867 \\
\hline & & Municipal & 36 & 5.327 \\
\hline & \multirow{2}{*}{ Privada } & Particular & 491 & 104.566 \\
\hline & & Comum./Confes./Filant. & 376 & 70.520 \\
\hline & \multicolumn{2}{|l|}{ Total } & 1.562 & 281.172 \\
\hline
\end{tabular}

Fonte: MEC/Inep/Daes (2001, 2004, 2006). 
A análise comparativa dos dados de 2001, 2004 e 2006, segundo a organização acadêmica das IES, também fornece informaçóes importantes a respeito do crescimento do número de cursos de Pedagogia e de alunos matriculados. Nota-se que o maior aumento relativo de cursos ocorreu nas universidades e centros universitários, uma vez que de 2001 a 2006 os percentuais de crescimento foram de $81 \%$ e 102\%, respectivamente. Cabe ressaltar, também, que nas faculdades isoladas, escolas e institutos superiores, o crescimento foi superior a 50\%; bem menor, portanto, do que nas modalidades institucionais universitárias; e o número de cursos nas faculdades integradas aumentou apenas $17 \%$.

Novamente, observa-se que o número de alunos não cresceu na mesma proporção que a quantidade dos cursos de Pedagogia, tal como se viu na análise comparativa feita, segundo a categoria administrativa das instituiçóes, em 2001, 2004 e 2006. Ao contrário, percebe-se certa estagnação e até a redução no número de alunos matriculados, notadamente nos centros universitários e nas faculdades integradas (Tabela 4).

Tabela 4 - Cursos de Pedagogia e respectivas matrículas, segundo a organização acadêmica das IES

\begin{tabular}{l|c|r|r|r|r}
\hline \multirow{2}{*}{ Organização Acadêmica } & \multirow{2}{*}{ Ano } & \multicolumn{2}{|c|}{ Curso } & \multicolumn{2}{c}{ Alunos matriculados } \\
\cline { 3 - 6 } & & $\mathbf{N}$ & \% & N & $\%$ \\
\hline \multirow{3}{*}{ Universidades } & 2001 & 547 & - & 129.729 & - \\
& 2004 & 941 & 72 & 162.073 & 25 \\
& 2006 & 989 & 81 & 168.728 & 30 \\
\hline \multirow{4}{*}{ Centros Universitários } & 2001 & 62 & - & 20.424 & - \\
& 2004 & 107 & 73 & 31.652 & 55 \\
& 2006 & 125 & 102 & 31.377 & 54 \\
\hline \multirow{3}{*}{ Faculdades Integradas } & 2001 & 60 & - & 18.896 & - \\
& 2004 & 68 & 13 & 17.650 & -7 \\
\hline \multirow{3}{*}{ Faculdades } & 2006 & 70 & 17 & 14.423 & -24 \\
\hline Escolas e ISE & 2001 & 250 & - & 51.857 & - \\
& 2004 & 321 & 28 & 66.651 & 29 \\
\hline Foladas, & 2006 & 378 & 51 & 66.644 & 29 \\
\hline
\end{tabular}

Fonte: MEC/Inep/Daes (2001, 2004, 2006). 


\section{CARACTERÍSTICAS DA AMOSTRA DOS CURSOS}

Para este estudo, foi selecionado um conjunto de cursos de Pedagogia, segundo os critérios de localização por regiáo (Norte, Nordeste, Centro-Oeste, Sudeste e Sul); segundo a categoria administrativa: pública (estadual, federal ou municipal) ou privada (particular ou comunitária, confessional ou filantrópica); e a organização acadêmica (universidade, centro universitário, faculdade integrada, faculdade isolada, escolas ou institutos superiores de educação). A composição final resultou em uma distribuiçãao proporcional à realidade do país. Tal coleta foi possível em razão da colaboração direta das instituiçóes de ensino superior, e outros dados foram obtidos complementarmente, mediante pesquisa da estrutura curricular de alguns cursos disponível na internet.

O conjunto amostral foi composto de 71 cursos presenciais de graduação em Pedagogia, distribuídos no país, mostrando boa representatividade em relação à distribuição proporcional por região, por categoria administrativa e organização acadêmica (Tabela 5).

Tabela 5 - Número de cursos, segundo a região

\begin{tabular}{l|c|c}
\hline \multicolumn{1}{c|}{ Região } & N & \% \\
\hline Norte & 6 & 8,5 \\
Nordeste & 12 & 16,9 \\
Sudeste & 30 & 42,3 \\
Sul & 13 & 18,3 \\
Centro-Oeste & 10 & 14,1 \\
\hline Total & $\mathbf{7 1}$ & $\mathbf{1 0 0 , 0}$ \\
\hline
\end{tabular}

$\mathrm{Na}$ distribuição das IES selecionadas, quanto à sua organização acadêmica, a preponderância na amostra, como no geral, foi de instituiçôes universitárias em todas as unidades da federação. Com relaçáo à dependência administrativa, como na distribuição dos cursos de Pedagogia no país, a maior parte dos que constam da amostra pertence a instituiçóes privadas (63\%), e assim se distribuem: $53 \%$ estão em universidades ou centros universitários, 38\% em faculdades e $9 \%$ em institutos superiores de educação. A Região Norte é a única em que predominam cursos em instituições públicas. 


\section{COMPOSIÇÃO DAS GRADES CURRICULARES DOS CURSOS DE LICENCIATURA EM PEDAGOGIA}

Foram listadas 3.513 disciplinas (3107 obrigatórias ${ }^{4}$ e 406 optativas) nas grades curriculares dos 71 cursos de Pedagogia. Realizou-se, então, um agrupamento de forma que se pudesse ter mais clareza do que se propóe como formação inicial de professores nos currículos das instituiçóes de ensino superior. Tal organização dos dados foi norteada, inicialmente, pelas orientaçôes contidas nas Diretrizes Curriculares Nacionais para o curso de licenciatura em Pedagogia, que englobam três grandes núcleos: 1) estudos básicos; 2) aprofundamento e diversificaçáo de estudos; 3) estudos integradores. No entanto, para diferenciar as estruturas curriculares, foi necessário especificar alguns aspectos que aparecem de maneira ampla nesses referidos núcleos. Elaboraram-se, assim, categorias de análise que permitissem dar conta dos vários aspectos presentes na formação do professor nas instituiçóes onde esta se realiza. A visão obtida é geral, não sendo aplicável a uma instituição em particular, mas sinaliza a tendência formativa do conjunto dos cursos. Entre estes, há grande variabilidade no que se refere às disciplinas oferecidas. Depois da análise de várias possibilidades, por se mostrarem aderentes ao conjunto de disciplinas nomeadas, as categorias definidas como referência de agrupamento para análise foram:

1. Fundamentos teóricos da educação - nessa categoria, estão presentes as disciplinas que cumprem a função de dar embasamento teórico ao aluno de Pedagogia a partir de outras áreas do conhecimento: Antropologia, Estatística, História, Psicologia, Sociologia, entre outras, e suas correlatas no campo da Educação. Por estar bem relacionada com o campo da Pedagogia, a Didática Geral foi destacada em um subgrupo passível de ser analisado separadamente.

2. Conhecimentos relativos aos sistemas educacionais - esse agrupamento comporta todas as disciplinas de conhecimento pedagógico, para a formação ampla na área de atuação do professor, bem como de outros profissionais da educaçáo. Inserem-se nessa categoria as matérias referentes:

- à estrutura e funcionamento do ensino: "Estrutura e Funcionamento da Educação Básica", "Financiamento da Educação Básica no Brasil", "Fundamentos da Gestão Educacional", "Legislação da Educação Básica", "Planejamento e Políticas Educacionais";

- ao currículo: "Avaliação da Aprendizagem”, "Currículo da Educação Básica I”, "Currículo e Avaliação”, "Currículo: Políticas e Práticas", "Currículos e

\footnotetext{
${ }^{4}$ Desse cômputo foram excluídos os estágios.
} 
Projeto Político Pedagógico", "Elaboração de Projetos Pedagógicos”;

- à gestão escolar: "Coordenação do Trabalho na Escola", "Dimensóes da Ação Supervisora", "Função do Diretor", "Gestáo da Unidade de Ensino", "Gestão e Coordenação do Trabalho Pedagógico no Ensino Fundamental (Supervisão, Administração e Orientação)"; "Organização do Trabalho Pedagógico";

- ao ofício docente: "Ensino e Identidade Docente", "Ética Profissional" e "Formação de Professores".

3. Conhecimentos relativos à formação profissional específica - nesse grupo, concentram-se as disciplinas que fornecem instrumental para atuação do professor, composto de:

- conteúdos do currículo da Educação Básica (infantil e fundamental): "Alfabetização e Letramento", "Arte e Educação", "Conhecimento Lógico-Matemático", "Educação Matemática", "Leitura e Escrita", "Língua Portuguesa”;

- didáticas específicas, metodologias e práticas de ensino: "Conteúdo e Metodologia de Língua Portuguesa", "Conteúdo e Metodologia de Matemática", "Didática do Ensino de História", "Fundamentos e Metodologia do Ensino de Ciências Naturais", "Fundamentos e Metodologia de Língua Portuguesa nos Anos Iniciais do Ensino Fundamental", "Fundamentos Teórico-Metodológicos do Ensino de Geografia", "Língua Portuguesa: Conteúdos e Didáticas", "Metodologia da Alfabetização e Letramento", "Metodologia do Ensino de Artes", Metodologia do Ensino da Educação Física", "Pesquisa em Educação na Prática de Ensino", "Prática de Ensino em Metodologia da Língua Portuguesa";

- $\quad$ saberes relacionados à tecnologia: "Gestão de Mídias Educacionais", "Informática Aplicada à Educação”, Recursos Tecnológicos para a Educação”, em enfoque de utilização.

\section{Conhecimentos relativos às modalidades e níveis de ensino específicos} - essa categoria reúne as disciplinas relacionadas às áreas de atuação de segmentos determinados. Nela foi incluída também a educação infantil, embora se trate de um nível educacional específico e não propriamente de uma modalidade de ensino, uma vez que o foco do trabalho recai predominantemente sobre o ensino fundamental.

- educação infantil: "Fundamentos da Educação Infantil”, "Didática do Ensino da Matemática na Educação Infantil”, "História da Educação Infantil”;

- $\quad$ educação especial: "Desenvolvimento e Aprendizagem: Especificidades das Pessoas com Deficiência”, "Educação Especial e Inclusão", "Concepção e Metodologia do Ensino de Deficiência Múltiplas"; 
- $\quad$ educação de jovens e adultos (EJA): "Educação de Adultos no Brasil: História e Política", "Fundamentos e Metodologia da Educação de Jovens e Adultos", "Iniciação à Pratica de Alfabetização de Jovens e Adultos";

- educação em contextos não escolares: "Conteúdos para a Formaçáo do Educador do 3o Setor", "Educação em Instituiçôes Não-escolares".

5. Outros saberes - disciplinas que ampliam o repertório do professor, como por exemplo: temas transversais, novas tecnologias, religiáo, etc.

6. Pesquisa e trabalho de conclusão de curso (TCC) - abarca todas as disciplinas que abordam as metodologias de pesquisa e a elaboração dos trabalhos de conclusão de curso, incluindo sua orientação.

7. Atividades complementares - referem-se às atividades integradoras, recomendadas pelas Diretrizes Curriculares Nacionais, ainda que sua denominação nos currículos seja vaga, não permitindo uma visão clara sobre o que contemplam de fato. Como exemplo, registram-se os rótulos: "Atividades científico-culturais", "Atividades complementares", "Estudos independentes", "Seminário Cultural”, etc.

As categorias de 1 a 4 possuem subcategorias que irão permitir a análise mais detalhada dos dados, como se verá no tópico seguinte.

Quanto aos Estágios, com carga horária definida nas Diretrizes Curriculares Nacionais, observou-se que as horas correspondentes são registradas como parte das estruturas curriculares, embora não se especifique como eles se realizam. Em razão de sua homogeneidade e especificidade, não foram computados para as proporçôes calculadas.

\subsection{Dados obtidos}

A variedade de nomenclatura de disciplinas encontradas em cada curso e entre os cursos de Pedagogia é imensa, o que sinaliza que o projeto de cada instituição procura sua vocação em diferentes aspectos do conhecimento, com enfoque próprio, o que se reflete na denominação das disciplinas. Nas 71 instituiçóes pesquisadas, foram encontradas 3.107 disciplinas registradas como obrigatórias, excluindo-se as que se referem a estágios, sugerindo, em média, 44 disciplinas obrigatórias por curso. Agregando a essas disciplinas o rol de optativas registradas, obtêm-se mais 406 disciplinas. A variação, de um curso para outro, do número de disciplinas propostas também é grande. Pensando que o número mínimo de horas prescrito para Pedagogia é de 3.200 e que 300 horas devem ser dedicadas ao estágio, pode-se inferir que o currículo efetivamente desenvolvido nesses cursos de formaçáo de professores tem uma característica fragmentária, com um conjunto disciplinar bastante disperso. 
Isto se confirma quando se examina o conjunto de disciplinas em cada curso, por semestre e em tempo sequencial, em que, normalmente, não se observam articulações curriculares entre as disciplinas.

Considerando o conjunto das instituições, há uma quase equivalência entre a proporção de disciplinas que cumprem a função de alicerçar teoricamente o aluno de Pedagogia com base em outras áreas de conhecimento e aquelas que tratam de questôes ligadas à profissionalização mais específica do professor. $\mathrm{Na}$ análise realizada sobre o conteúdo das ementas, verifica-se, no entanto, que as disciplinas que compóem a segunda categoria - "Conhecimentos relativos à formação profissional específica” - também têm em seus conteúdos uma predominância de aspectos teóricos, aqueles que fundamentam as teorias de ensino nas diversas áreas, contemplando pouco as possibilidades de práticas educacionais associadas a esses aspectos. As ementas das disciplinas desse grupo registram preocupação com as justificativas sobre "o porquê" ensinar, o que, de certa forma, contribuiria para evitar que essas matérias se transformassem em meros receituários. Entretanto, só de forma muito incipiente apontam "o quê" e "como" ensinar. Grande número de ementas apresenta frases genéricas não permitindo identificar conteúdos específicos. Há instituições que propóem o estudo dos conteúdos de ensino associados às metodologias mas, ainda assim, de forma panorâmica e pouco aprofundada. Então, mesmo nesse conjunto de $28 \%$ de disciplinas que podem ser classificadas como voltadas à formaçáo profissional específica, o que sugerem as ementas é que esta é feita de forma ainda muito insuficiente.

No grupo de disciplinas voltadas a outras modalidades de ensino (Educação de Jovens e Adultos, Educação Especial, entre outras) e à educação infantil, encontra-se nas ementas o mesmo cenário. Os cursos estáo incorporando tais questóes em um conjunto de disciplinas que acentuam abordagens mais genéricas ou descritivas das questôes educativas com poucas referências às práticas associadas. Poucos cursos dão a devida atençáo a essas modalidades educacionais, seja mediante a oferta de optativas, seja de tópicos e projetos especiais, mas neles não é possível detectar a predominância de elementos voltados para as práticas docentes propriamente ditas, como uma construção integrada a conhecimentos de fundo. As ementas revelam, antes de tudo, maior preocupação com o oferecimento de teorias sociológicas e psicológicas para a contextualização dos desafios do trabalho nessas modalidades de ensino.

Quando se agrega o conjunto de disciplinas dedicadas aos fundamentos teóricos da educação às disciplinas variadas e gerais que compóem o grupo dos "outros saberes" e das "atividades complementares", chega-se a quase $40 \%$ do conjunto 
de disciplinas oferecidas. Fica pouco claro o que nos currículos se qualifica como "atividades complementares". Juntando a esse panorama as disciplinas optativas, a maioria com caráter de formação genérica, pode-se inferir que a parte curricular que propicia o desenvolvimento de habilidades profissionais específicas para a atuação nas escolas e nas salas de aula fica bem reduzida. A relação teoria-prática proposta nos documentos legais e nas discussóes da área também se mostra comprometida desde essa base formativa.

A tabela 6 apresenta em detalhes as subcategorias curriculares de análise. Chama a atenção que, dos $26 \%$ de disciplinas que compóem a categoria "Fundamentos

Tabela 6 - Disciplinas obrigatórias, segundo as categorias e subcategorias de análise

\begin{tabular}{|c|c|c|c|}
\hline \multicolumn{2}{|c|}{ Categorias por Disciplina } & \multirow{2}{*}{$\begin{array}{c}\mathbf{N} \\
701 \\
106 \\
\mathbf{8 0 7} \\
\end{array}$} & \multirow{2}{*}{$\begin{array}{r}\% \\
22,6 \\
3,4 \\
\mathbf{2 6 , 0}\end{array}$} \\
\hline $\begin{array}{l}\text { Fundamentos teóricos da } \\
\text { educação }\end{array}$ & $\begin{array}{l}\text { Fundamentos teóricos da educação } \\
\text { Didática geral } \\
\text { Subtotal }\end{array}$ & & \\
\hline $\begin{array}{l}\text { Conhecimentos relativos aos } \\
\text { sistemas educacionais }\end{array}$ & $\begin{array}{l}\text { Sistemas educacionais } \\
\text { Currículo } \\
\text { Gestão escolar } \\
\text { Ofício docente } \\
\text { Subtotal }\end{array}$ & $\begin{array}{r}165 \\
158 \\
140 \\
19 \\
482\end{array}$ & $\begin{array}{r}5,3 \\
5,1 \\
4,5 \\
0,6 \\
15,5\end{array}$ \\
\hline $\begin{array}{ll}\text { Conhecimentos } & \text { relativos à } \\
\text { formação } & \text { profissional } \\
\text { específica } & \end{array}$ & $\begin{array}{l}\text { Conteúdos do currículo da Educação } \\
\text { Básica (infantil e fundamental) } \\
\text { Didáticas específicas, metodologias e } \\
\text { práticas de ensino } \\
\text { Tecnologias } \\
\text { Subtotal }\end{array}$ & $\begin{array}{r}643 \\
22 \\
897\end{array}$ & $\begin{array}{r}20,7 \\
0,7 \\
28,9\end{array}$ \\
\hline $\begin{array}{l}\text { Conhecimentos relativos às } \\
\text { modalidades e nível de } \\
\text { ensino }\end{array}$ & $\begin{array}{l}\text { Educação Especial } \\
\text { EJA } \\
\text { Educação Infantil } \\
\text { Contextos não escolares } \\
\text { Subtotal }\end{array}$ & $\begin{array}{r}118 \\
49 \\
165 \\
16 \\
348\end{array}$ & $\begin{array}{r}3,8 \\
1,6 \\
5,3 \\
0,5 \\
\mathbf{1 1 , 2}\end{array}$ \\
\hline Outros saberes & & 173 & 5,6 \\
\hline Pesquisa e TCC & & 217 & 7,0 \\
\hline Atividades complementares & & 183 & 5,9 \\
\hline Total & & 3.107 & 100,0 \\
\hline
\end{tabular}


teóricos da educação", apenas 3,4\% referem-se à "Didática geral". O grupo "Didáticas específicas, metodologias e práticas de ensino" (o "como" ensinar) representa $20,7 \%$ do conjunto, e apenas $7,5 \%$ das disciplinas são destinadas aos conteúdos a serem ensinados nas séries iniciais do ensino fundamental, ou seja, "o quê" ensinar. Esse dado torna evidente como os conteúdos específicos das disciplinas a serem ministradas em sala de aula não são objeto dos cursos de formação inicial do professor. Uma possibilidade a ser investigada é se esses conteúdos estão presentes nos cursos de metodologia, como se verá adiante.

Quanto aos "Conhecimentos relativos aos sistemas educacionais", verifica-se um equilíbrio entre as diferentes subcategorias, exceção feita às matérias que dizem respeito ao ofício docente (apenas 0,6\%). Dentre aquelas que compóem os "Conhecimentos relativos às modalidades e nível de ensino", nota-se que "Educação infantil" (5,3\%) e "Educação especial" (3,8\%) se destacam. Algumas instituiçóes abrem um pouco mais de espaço a um ou outro desses percursos de formação.

Observando o conjunto de disciplinas optativas oferecidas pelos cursos (Tabela 7), verifica-se a tendência em ofertar também disciplinas relativas a "Fundamentos Teóricos da Educação" (24\%), contemplando "Filosofia da Educação", "História da Educação", "Fundamentos Biológicos da Educação", "Antropologia da Educação", e assim por diante. Nesse grupo de disciplinas eletivas, é ainda menor o percentual daquelas voltadas à educação infantil, EJA ou educação especial, ou mesmo dos conhecimentos referentes ao magistério das séries iniciais do ensino fundamental.

Em torno de $25 \%$ das disciplinas se enquadram em "Outros saberes", como "Inglês Instrumental”, "Nutrição, higiene e saúde”, "O escolar e a droga”, etc., que consideram um rol de assuntos variados, muitos deles relativos aos temas transversais preconizados pelos Parâmetros Curriculares Nacionais, editados em 1997. 
Tabela 7 - Disciplinas optativas, segundo as categorias e subcategorias de análise

\begin{tabular}{|c|c|c|c|}
\hline \multicolumn{2}{|c|}{ Categorias por Disciplina } & $\mathbf{N}$ & $\%$ \\
\hline $\begin{array}{l}\text { Fundamentos teóricos da } \\
\text { educação }\end{array}$ & $\begin{array}{l}\text { Fundamentos teóricos da educação } \\
\text { Didática geral } \\
\text { Subtotal }\end{array}$ & $\begin{array}{r}93 \\
3 \\
96\end{array}$ & $\begin{array}{r}22,9 \\
0,7 \\
23,6\end{array}$ \\
\hline $\begin{array}{l}\text { Conhecimentos relativos aos } \\
\text { sistemas educacionais }\end{array}$ & $\begin{array}{l}\text { Sistemas educacionais } \\
\text { Currículo } \\
\text { Gestão escolar } \\
\text { Ofício docente } \\
\text { Subtotal }\end{array}$ & $\begin{array}{r}20 \\
14 \\
23 \\
8 \\
65\end{array}$ & $\begin{array}{r}4,9 \\
3,4 \\
5,7 \\
2,0 \\
16,0\end{array}$ \\
\hline $\begin{array}{ll}\text { Conhecimentos } & \text { relativos à } \\
\text { formação } & \text { profissional } \\
\text { específica } & \end{array}$ & $\begin{array}{l}\text { Conteúdos do currículo da Educação } \\
\text { Básica (infantil e fundamental) } \\
\text { Didáticas específicas, metodologias e } \\
\text { práticas de ensino } \\
\text { Tecnologias } \\
\text { Subtotal }\end{array}$ & $\begin{array}{l}24 \\
13 \\
63\end{array}$ & $\begin{array}{r}5,9 \\
3,2 \\
15,5\end{array}$ \\
\hline $\begin{array}{l}\text { Conhecimentos relativos às } \\
\text { modalidades e nível de } \\
\text { ensino }\end{array}$ & $\begin{array}{l}\text { Educação Especial } \\
\text { EJA } \\
\text { Educação Infantil } \\
\text { Contextos não escolares } \\
\text { Subtotal }\end{array}$ & $\begin{array}{r}16 \\
17 \\
14 \\
4 \\
51\end{array}$ & $\begin{array}{r}3,9 \\
4,2 \\
3,4 \\
1,0 \\
12,6\end{array}$ \\
\hline Outros saberes & & 101 & 24,9 \\
\hline Pesquisa e TCC & & 9 & 2,2 \\
\hline Atividades complementares & & 21 & 5,2 \\
\hline Total & & 406 & 100,0 \\
\hline
\end{tabular}

\subsection{Estágios supervisionados}

O número de horas de estágio obrigatório nos cursos de Pedagogia visa proporcionar aos alunos um contato mais aprofundado com as redes de ensino básico. Embora, em princípio, eles constituam espaços privilegiados para a aprendizagem das práticas docentes, não se obteve evidências, neste estudo, sobre como eles vêm sendo de fato realizados. Os dados referentes aos estágios padecem de uma série de imprecisôes. Embora a legislação obrigue a um mínimo de 300 horas de estágio, a metade dos cursos da amostra computa um número maior de horas do que o 
mínimo. Há instituições que oferecem, por exemplo, várias opções de estágio aos alunos, de acordo com as áreas por eles escolhidas (Estágio de Docência: 0 a 3 anos ou Estágio de Docência: 4 a 7 anos, Estágio de Docência: 6 a 10 anos, Estágio de Docência: Educação de Jovens e Adultos), e outras que apenas mencionam o total de horas destinadas; porém, sem nenhum detalhamento. Em algumas instituiçóes, os estágios são integrados às disciplinas, de sorte que não são feitas referências explícitas a eles. Essas imprecisóes praticamente inviabilizam a análise do que acontece realmente nesses espaços de formação com base apenas nos currículos. Não obstante, as observaçóes largamente difundidas sobre o funcionamento dos cursos de Pedagogia nos autorizam a sugerir que a maior parte dos estágios envolve atividades de observação nas escolas, não se constituindo em práticas efetivas para a formação de futuros professores.

O que se verificou na análise dos projetos e ementas dos cursos, é que não há especificação clara sobre como são realizados, supervisionados e acompanhados. Sobre a validade ou validação desses estágios também não se encontrou nenhuma referência. Não estão claros os objetivos, as exigências, formas de validação e documentação, acompanhamento, convênios com escolas das redes, etc. Essa ausência nos projetos e ementas pode sinalizar que, ou são considerados totalmente à parte do currículo, o que é um problema, na medida em que devem se integrar com as disciplinas formativas e com os aspectos da educação e da docência, ou sua realização é considerada um aspecto meramente formal. Um estudo mais aprofundado a respeito dos estágios para docência merece ser realizado.

\section{ANÁLISE DAS EMENTAS}

A análise das ementas e das grades curriculares foi construída com base em três questóes centrais:

- O que é possível constatar sobre as disciplinas relativas aos conteúdos específicos a serem ensinados pelos professores que se formam nos cursos de Pedagogia?

- O que é possível constatar acerca das disciplinas relativas aos métodos de ensino?

- O que é possível afirmar sobre a relação entre as disciplinas responsáveis pelos fundamentos dos conteúdos a serem estudados e as disciplinas responsáveis pelo desenvolvimento dos saberes e competências necessários à prática docente? 
Foi possível examinar 1.498 ementas. Observou-se que o entendimento a respeito da redação de uma ementa é diverso. A maioria dos proponentes entende que devem registrar uma lista de temas que formam o conjunto dos conteúdos trabalhados no período: um semestre ou um ano. Outros entendem por ementa a explicitação de certas concepçóes em apenas um parágrafo, podendo ser entendida também como explicitação de um objetivo geral. Outros, de forma mais aprofundada, elaboram ementa que busca expressar concepção e finalidade da disciplina. A diversidade de registros é significativa, mostrando formas bem variadas, seja um rol, uma lista, seja, em vários casos, um resumo, uma sinopse ou uma descrição conceitual de procedimentos. Estes últimos não são muitos ( $26 \%$ das ementas dos cursos); portanto, nas $74 \%$ restantes figura apenas o arrolamento de temas.

Considerando que o texto identificado como ementa é o resumo que facilita o acesso de alunos e demais interessados às intençóes de determinado curso, sua redação deveria ser mais cuidadosa. A adequação do texto das ementas à abordagem central, em termos de conteúdos e objetivos a serem trabalhados em sala de aula, torna-se relevante, pelo menos por três razóes:

- Revelar que o próprio professor conhece e sabe dizer de forma sintética o conjunto de temas a serem abordados para a formaçáo dos futuros educadores.

- Comunicar aos alunos os compromissos da disciplina, auxiliando no acompanhamento do currículo. $\mathrm{O}$ acesso dos alunos aos programas de ensino tem viabilizado movimentos discentes mais fundamentados e críticos em relação ao trabalho dos professores.

- Ainda que menos relevante para o bom andamento do currículo, a redação adequada de ementas auxilia pesquisadores a se aproximarem de forma mais rigorosa do trabalho proposto em diferentes projetos pedagógicos.

No caso específico desta pesquisa, a leitura das ementas permitiu constatar fragilidades não apenas em termos de redação propriamente dita, mas também no que se refere ao não favorecimento de uma compreensão mais clara dos temas propostos, e de se avaliar ou verificar os objetivos subjacentes ou explícitos no tempo de duração da disciplina.

\subsection{Conteúdos específicos a serem ensinados}

Os conteúdos a serem ensinados pelos professores aos alunos das séries iniciais do ensino fundamental, da educação infantil e da EJA estão circunscritos às áreas de Alfabetização, Língua Portuguesa, Matemática, História, Geografia, Artes, Ciên- 
cias, Educação Física, em princípio tendo em conta os conhecimentos e valores que devem estar presentes em cada nível educacional ou modalidade de ensino.

Dentre as universidades públicas analisadas, nenhuma oferece disciplina específica para os conteúdos substantivos de cada área, nem mesmo para Língua Portuguesa e Matemática. Tais conteúdos permanecem implícitos nas disciplinas relativas às metodologias de ensino, ou na concepção de que eles são de domínio dos alunos dos cursos de formação. Algumas poucas ementas desta categoria identificam o tratamento dispensado aos conteúdos específicos a serem ensinados nas escolas de ensino fundamental.

No caso das instituições privadas, a leitura das ementas de Língua Portuguesa permite afirmar que existem duas formas de apresentação dessa disciplina: uma, cujos conteúdos abordam os conhecimentos específicos da área, sem incluir aqueles a serem ensinados pelos futuros professores, e outra, cujos conteúdos se referem diretamente ao ensinar. No primeiro grupo, incluem-se as disciplinas Linguística e Língua Portuguesa, com referência a conteúdos de aprofundamento ou que sugerem preparo dos futuros professores para uso da língua, independentemente da sua tarefa de ensinar. No segundo grupo, figura a disciplina Alfabetização e Metodologia do Ensino da Língua Portuguesa. Certamente os dois grupos colaboram para a construção de competências para ensinar, se a metodologia do ensino de Língua Portuguesa estiver articulada aos conteúdos específicos, com a profundidade e a particularidade próprias desse campo. Mas ainda há aqui a tradiçáa de se propor aprofundamento teórico sem o correlativo das práticas profissionais. As ementas das disciplinas associadas a Ciências, Geografia, História, Educação Física e até Matemática indicam que os cursos oferecem um panorama sobre os conteúdos específicos sem o aprofundamento necessário e sem associá-los a perspectivas didáticas. Uma última observação: dentre as ementas examinadas, a referência à palavra "escola" é encontrada em apenas 8\% delas.

Segundo as Diretrizes Curriculares Nacionais (Brasil, 2006), a estrutura do curso de Pedagogia deve ser constituída de três núcleos: estudos básicos, aprofundamento e diversificação de estudos e estudos integradores, como mencionado. $\mathrm{O}$ núcleo de estudos básicos é descrito, no referido documento, com a predominância da palavra aplicação e realização: "aplicação, em práticas educativas, de conhecimentos de processos de desenvolvimento de crianças...”; "aplicação de princípios, concepçóes e critérios oriundos de diferentes áreas de conhecimentos...”, sinalizando que os conteúdos desenvolvidos durante o curso devem ser estudados em uma vertente prática, aliada a seus fundamentos, para que se construam competências de aplicabilidade. 
Pode-se perguntar se a formação panorâmica, geralmente encontrada nos currículos, é suficiente para o futuro professor vir a planejar, ministrar e avaliar atividades de ensino para os anos iniciais da educação básica.

\section{SÍNTESE E CONSIDERAÇÕES FINAIS}

Pela análise realizada foi possível constatar que: a) o currículo proposto pelos cursos de formação de professores tem uma característica fragmentária, apresentando um conjunto disciplinar bastante disperso; b) a análise das ementas revelou que, mesmo dentre as disciplinas de formação específica, predominam as abordagens de caráter mais descritivo e que se preocupam menos em relacionar adequadamente as teorias com as práticas; c) as disciplinas referentes à formação profissional específica apresentam ementas que registram preocupação com as justificativas sobre "o porquê" ensinar, o que, de certo modo, contribuiria para evitar que essas matérias se transformassem em meros receituários; entretanto, só de forma muito incipiente registram "o quê" e "como" ensinar; d) a proporção de horas dedicadas às disciplinas referentes à formação profissional específica é de 30\%, ficando $70 \%$ para as outras matérias oferecidas nas instituiçóes formadoras. Cabe a ressalva, já feita na análise das ementas, segundo a qual, nas disciplinas de formação profissional, predominam os referenciais teóricos de natureza sociológica, psicológica ou outros, com associação em poucos casos às práticas educacionais; e) os conteúdos das disciplinas a serem ensinados na educação básica (Alfabetização, Língua Portuguesa, Matemática, História, Geografia, Artes, Ciências, Educação Física) são tratados esporadicamente nos cursos de formação, e, na maioria dos cursos analisados, são abordados de forma genérica ou superficial, sugerindo frágil associação com as práticas docentes; f) poucos cursos propóem disciplinas que permitam algum aprofundamento em relação à educação infantil.

Nas ementas, observou-se um evidente desequilíbrio na relação teoria-prática, em favor dos tratamentos mais teóricos, de fundamentos e contextualização, e a escola, como instituição social e de ensino, é elemento quase ausente nas ementas, o que leva a pensar em uma formação de caráter mais abstrato, e pouco integrada ao contexto concreto onde o profissional-professor vai atuar.

Pelo estudo, pode-se inferir que a parte curricular que propicia o desenvolvimento de habilidades profissionais específicas para a atuação nas escolas e nas salas de aula fica bem reduzida. Assim, a relaçáo teoria-prática, como proposta nos documentos legais e nas discussóes da área, também se mostra comprometida desde essa base formativa. 


\section{REFERÊNCIAS BIBLIOGRÁFICAS}

BRASIL. Ministério da Educação. Conselho Nacional de Educação. Resolução CNE/CP 1, 18 fev. 2002. Institui as Diretrizes Curriculares Nacionais para a Formação de Professores da Educação Básica, em nível superior, curso de licenciatura, de graduação plena. Brasília, 2002. . Resolução CNE/CP 2, 19 fev. 2002. Institui a duração e a carga horária dos cursos de licenciatura, de graduação plena, de formação de professores da Educação Básica em nível superior. Brasília, 2002.

. Resolução de 1 de maio de 2006:

Diretrizes curriculares nacionais para o curso de Pedagogia. Brasília, 2006.

BRASIL. Ministério da Educação. Instituto Nacional de Estudos e Pesquisas Educacionais Anísio Teixeira. Portaria no 124, 7 ago. 2008.
Brasília, 2008.

. Sinopse Estatística da Educação Superior. Brasília, 2001. Disponível em: <http:// www.inep.gov.br/superior/censosuperior/ sinopse/>.

- Sinopse Estatística da Educação

Superior. Brasília, 2004. Disponível em: <http:// www.inep.gov.br/superior/censosuperior/ sinopse/>.

- Sinopse Estatística da Educação Superior. Brasília, 2006a. Disponível em: <http:// www.inep.gov.br/superior/censosuperior/ sinopse/>.

BRASIL. Ministério de Educação. Secretaria de EducaçãoFundamental.ParâmetrosCurriculares Nacionais para o ensino fundamental. Brasília, 1997.

Recebido em: maio 2009

Aprovado para publicação em: junho 2009 